\title{
A New Sesquiterpene from Schisandra sphenanthera
}

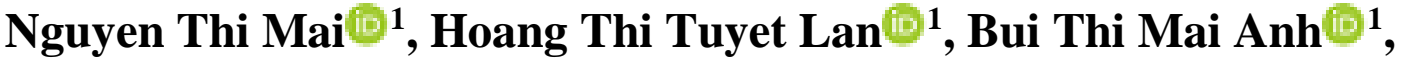 \\ Vu Van Doan ${ }^{2}$, Bui Huu Tai ${ }^{2,3}$, Nguyen Xuan Nhiem ${ }^{2,3}$ and \\ Phan Van Kiem 2,3* \\ ${ }^{1}$ University of Transport and Communications, 3 Cau Giay, Dong Da, Ha Noi, Vietnam \\ ${ }^{2}$ Institute of Marine Biochemistry, Vietnam Academy of Science and Technology (VAST), 18 \\ Hoang Quoc Viet, Cau Giay, Hanoi, Vietnam \\ ${ }^{3}$ Graduate University of Science and Technology, VAST, 18 Hoang Quoc Viet, Cau Giay, Hanoi, \\ Vietnam
}

(Received September 12, 2019; Revised October 01, 2019; Accepted October 03, 2019)

\begin{abstract}
A new sesquiterpene, schisandrathera E (1) and seven dibenzocyclooctadiene lignans as schisantherin D (2), schisantherin B (3), tigloylgomisin P (4), schisphenin E (5), angeloylgomisin H (6), (+)-deoxyschizandrin (7), and (+)-gomisin $\mathrm{K}_{3}(\mathbf{8})$ were isolated from the leaves of Schisandra sphenanthera Rehder \& E.H.Wilson. Their structures were elucidated by spectroscopic and mass spectrometric analyses, including 1D-, 2D-NMR, HR-ESI-MS and ECD spectra. Compound $\mathbf{1}$ displayed moderate cytotoxicity against both PC 3 and MCF4 cell lines in MTT assay with $\mathrm{IC}_{50}$ values of 22.60 and $7.80 \mu \mathrm{M}$, respectively.
\end{abstract}

Keywords: Schisandra sphenanthera; schisandrathera ; sesquiterpene; dibenzocyclooctadiene. @ 2020 ACG Publications. All rights reserved.

\section{Introduction}

The plant Schisandra sphenanthera has been used as a traditional herb to treat for various types of diseases including cough, diarrhea, diabetes, insomnia [1]. The phytochemistry investigation of this plant resulted in numerous lignan compounds [2-4]. In the course of searching for new bio-active compounds from natural resources, we reported herein the isolation procedure and chemical structural elucidation of a new sesquiterpene, schisandrathera $\mathrm{E}$ (1), together with seven known dibenzocyclooctadiene lignans (2-8) including four $S$-biphenyl and three $R$-biphenyl configurations of $\mathrm{C}_{18}$-dibenzocyclooctadiene skeleton from the leaves of $S$. sphenanthera. Their chemical structures were extensively elucidated by using means of 1D, 2D-NMR experiments and compared their NMR data with the published values. In addition, the stereochemistry of 1 was successfully determined by both theoretical and calculated CD spectra, as well as all eight isolated compounds were tested for cytotoxic activity against two cancer cell lines PC3 and MCF4.

\footnotetext{
*Corrseponding author: E-Mail: phankiem@yahoo.com
} 


\section{Materials and Methods}

\subsection{General}

The ESI-MS and HR-ESI-MS were taken using an Agilent 6530 Q-TOF LC/MS systems. NMR spectra were recorded on a Bruker AM500 FT-NMR spectrometer with TMS as an internal Standard. Column chromatography (CC) was performed using Kieselgel 60, 70-230 mesh and 230-400 mesh (Merck, Darmstadt, Germany). Thin layer chromatography (TLC) used pre-coated silica gel 60 F254 (Merck, Darmstadt, Germany). Preparative HPLC were carried out on an Agilent 1100 system (Agilent technologies, Santa Clara, CA, USA), using J'sphere ODS-H80 semi-preparative column (20×250 mm, YMC, Kyoto, Japan).

\subsection{Plant Material}

The leaves of Schisandra sphenanthera Rehder \& E.H.Wilson were collected in Kon Tum province in February 2017, and identified by Dr. Nguyen The Cuong, Institute of Ecology and Biological Resources. A voucher specimen (NCCT-P110) was deposited at the Institute of Marine Biochemistry.

\subsection{Extraction and Isolation}

The dried plant $(5.0 \mathrm{~kg}$ ) was powdered and sonicated with $\mathrm{MeOH}$ three times (each time $10 \mathrm{~L}$ ) at room temperature. The crude $\mathrm{MeOH}(220 \mathrm{~g})$ extract was obtained by solvent evaporation under reduced pressure, which was suspended with water and partitioned with dichloromethane, ethyl acetate to give $22.3 \mathrm{~g}$ dichloromethane, $70.0 \mathrm{~g}$ ethyl acetate extracts and water layer. The ethyl acetate crude part was first chromatographed on a silica gel column using a stepwise gradient of hexane/ethyl acetate to give seven fractions ESS1-ESS7. Fraction ESS1 was subjected to a reserve phase C-18 (RP$18)$ and eluted with acetone/water $(1.5 / 1 \mathrm{v} / \mathrm{v})$ to give six smaller fractions ESS1.1- ESS1.6. Purification ESS1.2 fraction with eluent of hexane/ethyl acetate $(5 / 1 \mathrm{v} / \mathrm{v})$ resulted in four fractions ESS1.2.1-ESS1.2.4. Compounds $4(4.8 \mathrm{mg})$ and $\mathbf{5}(4.4 \mathrm{mg})$ were isolated from ESS1.2.2 by using preparative HPLC column eluting with acetonitrile/water (4/1 v/v). Fraction ESS1.2.3 was subjected to a silica gel CC eluting with hexane/ethyl acetate $(4 / 1 \mathrm{v} / \mathrm{v})$ to give five fractions ESS1.2.3AESS1.2.3E. Compound 7 was obtained from ESS1.2.3B by using preparative HPLC column eluting with acetonitrile/water $(5.5 / 1 \mathrm{v} / \mathrm{v})$. Compounds $2(6.5 \mathrm{mg})$ and $8(5.0 \mathrm{mg})$ were isolated from ESS1.2.3D by using preparative HPLC column eluting with acetonitrile/water $(4.5 / 1 \mathrm{v} / \mathrm{v})$ while compound $3(4.0 \mathrm{mg})$ was purified from ESS1.2.3E by using preparative HPLC column and eluting with acetonitrile/water column (4/1 v/v). ESS3 fraction was subjected to a RP-18 CC using acetone/water $(0.8 / 1 \mathrm{v} / \mathrm{v})$ as eluent to give five fractions ESS3.1-ESS3.5. Fraction ESS3.5 was loaded into a silica gel CC eluting with hexane/ethyl acetate $(3.7 / 1 \mathrm{v} / \mathrm{v})$ to get compound $6(4.3 \mathrm{mg})$. Fraction ESS1.2.3 was chromatographed on a silica gel CC eluting with hexane/acetone $(10 / 1 \mathrm{v} / \mathrm{v})$ to get fraction ESS1.2.3A, which was further purified by preparative HPLC column eluting with acetonitrile/water $(49 / 1 \mathrm{v} / \mathrm{v})$ to give compound $1(6.3 \mathrm{mg})$.

Schisandrathera $E$ (1): Colorless oil, $[\alpha]_{D}^{26}-8.4^{\circ}(c=0.1, \mathrm{MeOH})$; HR-ESI-MS: $m / z 257.1897[\mathrm{M}+\mathrm{Na}]^{+}$ (calcd. for $\mathrm{C}_{16} \mathrm{H}_{26} \mathrm{ONa}$ : 257.1881); ${ }^{1} \mathrm{H}-\mathrm{NMR}$ and ${ }^{13} \mathrm{C}-\mathrm{NMR}$, see Table 1 .

Schisantherin $D(2)$ : Colorless prisms, $[\alpha]_{D}^{26}-130^{\circ}\left(c=0.5\right.$, MeOH); ESI-MS: $m / z 521[\mathrm{M}+\mathrm{H}]^{+} ;{ }^{1} \mathrm{H}-$ NMR and ${ }^{13} \mathrm{C}-\mathrm{NMR}$, see Table S1, S2.

Schisantherin B (3): Colorless prisms, $[\alpha]_{D}^{26}-30^{\circ}\left(c=0.3\right.$, MeOH); ESI-MS: $m / z 515[\mathrm{M}+\mathrm{H}]^{+} ;{ }^{1} \mathrm{H}-\mathrm{NMR}$ and ${ }^{13} \mathrm{C}-\mathrm{NMR}$, see Table S1, S2.

Tigloylgomisin P (4): Colorless prisms, $[\alpha]_{D}^{26}-42^{\circ}\left(c=0.4\right.$, MeOH); ESI-MS: $m / z 515[\mathrm{M}+\mathrm{H}]^{+} ;{ }^{1} \mathrm{H}-$ NMR and ${ }^{13} \mathrm{C}$-NMR, see Table S1, S2. 
Schisphenin E (5): Colorless prisms, $[\alpha]_{D}^{26}-22^{\circ}\left(c=0.5\right.$, MeOH); ESI-MS: $m / z 433[\mathrm{M}+\mathrm{H}]^{+} ;{ }^{1} \mathrm{H}-\mathrm{NMR}$ and ${ }^{13} \mathrm{C}-\mathrm{NMR}$, see Table S1, S2.

Angeloylgomisin $H(6)$ : Amorphous solid, $[\alpha]_{D}^{26}+112^{\circ}\left(c=0.4\right.$, MeOH); ESI-MS: $m / z 501[\mathrm{M}+\mathrm{H}]^{+} ;{ }^{1} \mathrm{H}-$ NMR and ${ }^{13}$ C-NMR, see Table S3.

(+)-Deoxyschizandrin (7): Amorphous solid, $[\alpha]_{D}^{26}+15^{\circ}\left(\mathrm{c}=0.4\right.$, MeOH); ESI-MS: m/z $417[\mathrm{M}+\mathrm{H}]^{+}$; ${ }^{1} \mathrm{H}-\mathrm{NMR}$ and $13 \mathrm{C}-\mathrm{NMR}$, see Table S3.

(+)-Gomisin $K_{3}(8)$ : Colorless needles, $[\alpha]_{D}^{26}+65^{\circ}(\mathrm{c}=0.4, \mathrm{MeOH})$; ESI-MS: m/z $403[\mathrm{M}+\mathrm{H}]^{+} ;{ }^{1} \mathrm{H}-$ NMR and ${ }^{13} \mathrm{C}-\mathrm{NMR}$, see Table S3.

\section{Results and Discussion}

\subsection{Structure Elucidation}

Compound 1 was obtained as colorless oil, which exhibited an ion peak at $\mathrm{m} / \mathrm{z} 257.1897[\mathrm{M}+$ $\mathrm{Na}]^{+}$in HR-ESI-MS (Figure S1) confirming its molecular formula of $\mathrm{C}_{16} \mathrm{H}_{26} \mathrm{O}$ (calcd. for $\mathrm{C}_{16} \mathrm{H}_{26} \mathrm{ONa}$ : 257.1881 ), indicating four degrees of unsaturation. The ${ }^{1} \mathrm{H}-\mathrm{NMR}$ spectrum displayed two aromatic protons at $\delta_{\mathrm{H}} 5.78(\mathrm{~d}, J=7.5 \mathrm{~Hz})$ and $5.52(\mathrm{dt}, J=7.5,2.0)$, a methoxy group at $\delta_{\mathrm{H}} 3.28(\mathrm{~s})$, three methyl groups including one upfield singlet at $\delta_{\mathrm{H}} 0.84$, and two doublets at $\delta_{\mathrm{H}} 0.93(\mathrm{~d}, J=7.0 \mathrm{~Hz})$ and $0.99\left(\mathrm{~d}, J=7.0 \mathrm{~Hz}\right.$ ) (Figure S2). The ${ }^{13} \mathrm{C}-\mathrm{NMR}$ and HSQC spectra (Figure S3-4) of 1 exhibited sixteen carbons, which were assigned for a sesquiterpene and a methoxy group as shown in Table 1. Two $>\mathrm{C}=\mathrm{CH}$ - double bonds were identified at $\delta_{\mathrm{C}} 113.9,122.5,138.3$, and 159.8, an oxygenated methylene group was assigned at $\delta_{\mathrm{C}} 79.7$. Compound 1 was suggested to contain two rings by analyzing of NMR data and above mass spectrum by using degrees of unsaturation as shown in Figure 1.
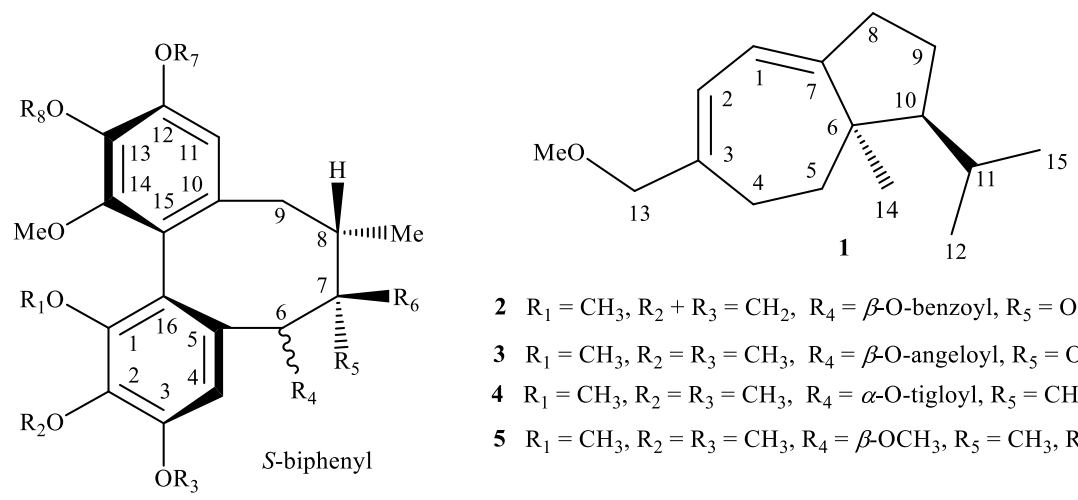

$2 \mathrm{R}_{1}=\mathrm{CH}_{3}, \mathrm{R}_{2}+\mathrm{R}_{3}=\mathrm{CH}_{2}, \mathrm{R}_{4}=\beta$-O-benzoyl, $\mathrm{R}_{5}=\mathrm{OH}, \mathrm{R}_{6}=\mathrm{CH}_{3}, \mathrm{R}_{7}+\mathrm{R}_{8}=\mathrm{CH}_{2}$
$3 \mathrm{R}_{1}=\mathrm{CH}_{3}, \mathrm{R}_{2}=\mathrm{R}_{3}=\mathrm{CH}_{3}, \mathrm{R}_{4}=\beta$-O-angeloyl, $\mathrm{R}_{5}=\mathrm{OH}, \mathrm{R}_{6}=\mathrm{CH}_{3}, \mathrm{R}_{7}+\mathrm{R}_{8}=\mathrm{CH}_{2}$
$4 \mathrm{R}_{1}=\mathrm{CH}_{3}, \mathrm{R}_{2}=\mathrm{R}_{3}=\mathrm{CH}_{3}, \mathrm{R}_{4}=\alpha$-O-tigloyl, $\mathrm{R}_{5}=\mathrm{CH}_{3}, \mathrm{R}_{6}=\mathrm{OH}, \mathrm{R}_{7}+\mathrm{R}_{8}=\mathrm{CH}_{2}$
$5 \mathrm{R}_{1}=\mathrm{CH}_{3}, \mathrm{R}_{2}=\mathrm{R}_{3}=\mathrm{CH}_{3}, \mathrm{R}_{4}=\beta$-OCH $, \mathrm{R}_{5}=\mathrm{CH}_{3}, \mathrm{R}_{6}=\mathrm{R}_{7}=\mathrm{H}, \mathrm{R}_{8}=\mathrm{CH}_{3}$

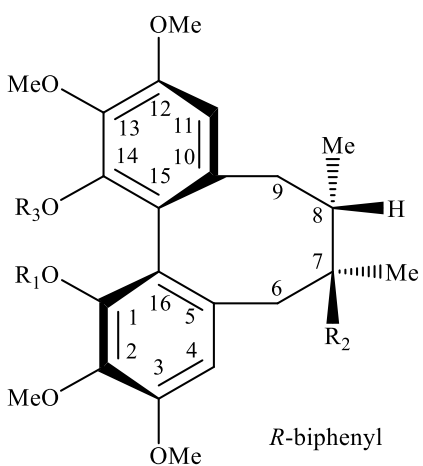

$6 \mathrm{R}_{1}=\mathrm{CH}_{3}, \mathrm{R}_{2}=\mathrm{OH}, \mathrm{R}_{3}=$-angeloyl

$7 \mathrm{R}_{1}=\mathrm{CH}_{3}, \mathrm{R}_{2}=\mathrm{H}, \mathrm{R}_{3}=\mathrm{CH}_{3}$

$8 \mathrm{R}_{1}=\mathrm{CH}_{3}, \mathrm{R}_{2}=\mathrm{R}_{3}=\mathrm{H}$

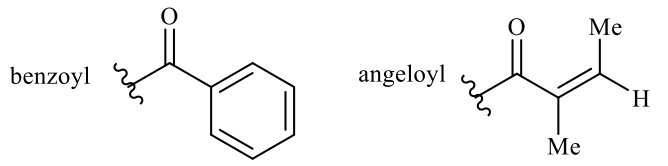<smiles>CC=CC(=O)C(C)=CC</smiles>

Figure 1. The chemical structures of compounds 1-8

Furthermore, cross peaks from H-1 $\left(\delta_{\mathrm{H}} 5.52\right)$ to $\mathrm{H}-2\left(\delta_{\mathrm{H}} 5.78\right)$, from $\mathrm{H}-4\left(\delta_{\mathrm{H}} 2.34\right)$ to $\mathrm{H}-5\left(\delta_{\mathrm{H}}\right.$ $2.00 / 1.39)$, from $\mathrm{H}-9\left(\delta_{\mathrm{H}} 1.86 / 1.48\right)$ to $\mathrm{H}-8\left(\delta_{\mathrm{H}} 2.44 / 2.32\right)$ and $\mathrm{H}-10\left(\delta_{\mathrm{H}} 1.32\right)$, and from $\mathrm{H}-11\left(\delta_{\mathrm{H}} 1.71\right)$ 
to $\mathrm{H}-10, \mathrm{H}-12\left(\delta_{\mathrm{H}} 0.99\right)$, and $\mathrm{H}-15\left(\delta_{\mathrm{H}} 0.93\right)$ were observed in the ${ }^{1} \mathrm{H}-{ }^{1} \mathrm{H}$ COSY spectrum of 1 confirming its structural fragmentations (Figure S6, S8). In addition, the HMBC correlations from olefinic proton $\mathrm{H}-1$ to $\mathrm{sp}^{3}$ non-protonated carbons $\mathrm{C}-3\left(\delta_{\mathrm{C}} 138.3\right)$ and $\mathrm{C}-6\left(\delta_{\mathrm{C}} 47.8\right)$, from $\mathrm{H}-2$ to $\mathrm{C}-$ 7/C3/C-4, from H-5 to C-3/C-6/C-7, from H-13 to C-2/C-3/C-4, from methoxy protons $\left(\delta_{\mathrm{H}} 3.85\right)$ to C13 , and from $\mathrm{H}-14$ to $\mathrm{C}-5 / \mathrm{C}-6 / \mathrm{C}-7$ were observed confirming two double bonds were at $\mathrm{C}-1 / \mathrm{C}-7$ and $\mathrm{C}-2 / \mathrm{C}-3$, methoxy group linked to $\mathrm{C}-13$, and the methyl group was at $\mathrm{C}-6$, as well as the presence of 1(methoxymethyl)-6,7-disubstituted-cyclochepta-1,3-diene was established. The HMBC interactions between $\mathrm{H}-8$ and C-7/C-10, between $\mathrm{H}-9$ and C-6/C-7/C-10 and from $\mathrm{H}-1$ to $\mathrm{C}-8$ suggested that fivemember ring was fused with 1-(methoxymethyl)-6,7-disubstituted-cyclochepta-1,3-diene at C-6 and C-7. Moreover, the HMBC interactions from two methyl groups together with $\mathrm{H}-11$ to sp ${ }^{3}$ methine C10 suggested that isopropyl unit attached to $\mathrm{C}-10$ of five-member carbon ring (Figure S5, S8). The overall planar structure of $\mathbf{1}$ was quite similar with that of hortonones B, except for the addition of a methoxy group and the disappearance of the ketone functional group [5].

Table 1. NMR data for compound 1

\begin{tabular}{cll}
\hline Position & \multicolumn{1}{c}{$\boldsymbol{\delta}_{\mathbf{C}^{\mathbf{a}, \mathbf{b}}}$} & \multicolumn{1}{c}{$\boldsymbol{\delta}_{\mathbf{H}}^{\mathbf{a , c}}$} \\
\hline 1 & $113.9(\mathrm{CH})$ & $5.52(1 \mathrm{H}, \mathrm{dt}, J=7.5,2.0 \mathrm{~Hz})$ \\
2 & $122.5(\mathrm{CH})$ & $5.78(1 \mathrm{H}, \mathrm{d}, J=7.5 \mathrm{~Hz})$ \\
3 & $138.3(\mathrm{C})$ & - \\
4 & $28.0\left(\mathrm{CH}_{2}\right)$ & $2.34(2 \mathrm{H}, \mathrm{m})$ \\
5 & $33.9\left(\mathrm{CH}_{2}\right)$ & $2.00(1 \mathrm{H}, \mathrm{m})$ \\
& & $1.39(1 \mathrm{H}, \mathrm{m})$ \\
6 & $47.8(\mathrm{C})$ & - \\
7 & $159.8\left(\mathrm{C}^{2}\right.$ & - \\
8 & $31.8\left(\mathrm{CH}_{2}\right)$ & $2.44(1 \mathrm{H}, \mathrm{dd}, J=17.5,8.5 \mathrm{~Hz})$ \\
& & $2.32(1 \mathrm{H}, \mathrm{m})$ \\
9 & $27.0\left(\mathrm{CH}_{2}\right)$ & $1.81(1 \mathrm{H}, \mathrm{m})$ \\
& & $1.48(1 \mathrm{H}, \mathrm{m})$ \\
10 & $57.6(\mathrm{CH})$ & $1.32(1 \mathrm{H}, \mathrm{m})$ \\
11 & $28.3\left(\mathrm{CH}^{2}\right)$ & $1.71(1 \mathrm{H}, \mathrm{m})$ \\
12 & $24.1\left(\mathrm{CH}_{3}\right)$ & $0.99(3 \mathrm{H}, \mathrm{d}, J=7.0 \mathrm{~Hz})$ \\
13 & $79.7\left(\mathrm{CH}_{2}\right)$ & $3.85(2 \mathrm{H}, \mathrm{s})$ \\
14 & $15.6\left(\mathrm{CH}_{3}\right)$ & $0.84(3 \mathrm{H}, \mathrm{s})$ \\
15 & $22.3\left(\mathrm{CH}_{3}\right)$ & $0.93(3 \mathrm{H}, \mathrm{d}, J=7.0 \mathrm{~Hz})$ \\
$\mathrm{OMe}$ & $57.2\left(\mathrm{CH}_{3}\right)$ & $3.28(3 \mathrm{H}, \mathrm{s})$ \\
\hline
\end{tabular}

Measured in a) $\mathrm{CDCl}_{3},{ }^{\text {b) }} 125 \mathrm{MHz},{ }^{\mathrm{c}} 500 \mathrm{MHz}$

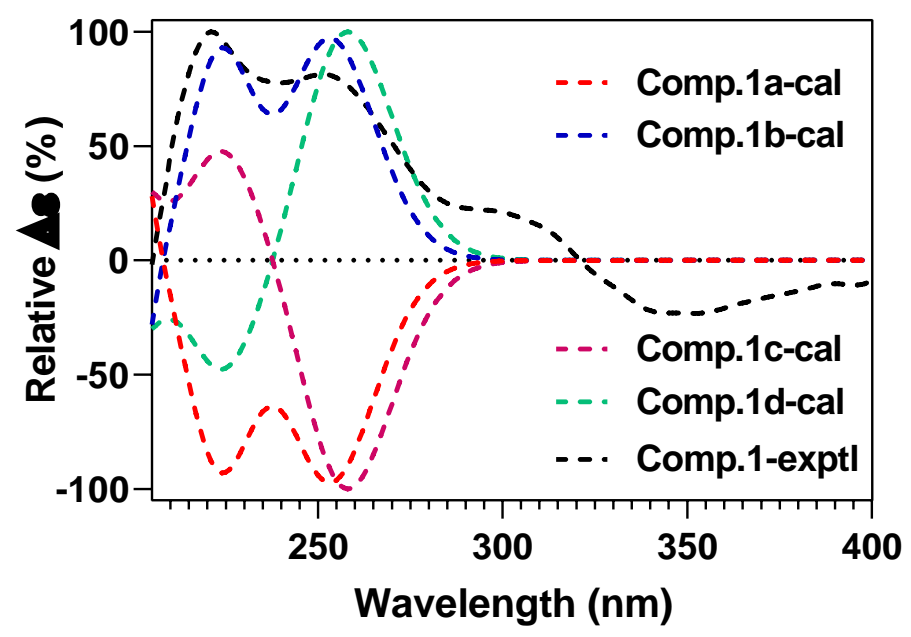

Figure 2. Theoretical calculated ECD spectra of four possible stereoisomers and experimental CD for compound 1 
Finally, the absolute configurations of two stereogenic centers at C-6 and C-10 in 1 were determined by both experimental and calculated ECD analysis. Four possible configurations 1a$(6 S, 10 R), 1 \mathrm{~b}-(6 R, 10 S), 1 \mathrm{c}-(6 R, 10 R)$, and $1 \mathrm{~d}-(6 S, 10 S)$ were submitted to calculate their theoretical ECD spectra and compared with experimental results (Figure 2). The experimental CD analysis displayed two positive CEs at 221 and $253 \mathrm{~nm}$, which were in good agreements with $\mathbf{1 b}$ (two positive CEs at 223 and $253 \mathrm{~nm}$ ). Consequently, the complete structure of compound 1 was elucidated as shown in Figure 1, a new sesquiterpene named as schisandrathera E.

In addition, the remaining seven dibenzocyclooctadiene lignans were determined as schisantherin D (2) [6], schisantherin B (3) [4], tigloylgomisin P (4) [7], schisphenin E (5) [8], angeloylgomisin $\mathrm{H}$ [7], (+)-deoxyschizandrin [9], (+)-gomisin $\mathrm{K}_{3}(\mathbf{8})$ [10] by comparing their NMR data with that in the reported literatures.

\subsection{Cytotoxicity Activity}

The cytotoxic behavior of these compounds 1-8 were evaluated against two cancer cell lines following MTT assay [11]. At concentration of $30 \mu \mathrm{M}$, compounds 2-6 were inactive as less than $50 \%$ of dead cells were observed. Compound 1 displayed moderate cytotoxicity toward both PC3 and MCF4 cell lines with $\mathrm{IC}_{50}$ values of 22.60 and $7.80 \mu \mathrm{M}$, respectively, while capecitabine was used as positive control with $\mathrm{IC}_{50}$ values of 11.2 and $7.17 \mu \mathrm{M}$, respectively. The $\mathrm{IC}_{50}$ values of compounds 7-8 were calculated and tabulated in table S5.

\section{Acknowledgment}

This work was financially supported by the Ministry of Education and Training under grant number HH01, 2019.

\section{Supporting Information}

Supporting information accompanies this paper on http://www.acgpubs.org/journal/records-ofnatural-products

\section{ORCID}

Nguyen Thi Mai: 0000-0002-3683-239X

Hoang Thi Tuyet Lan: 0000-0001-6693-3557

Bui Thi Mai Anh: 0000-0003-4504-048X

Vu Van Doan: 0000-0001-5229-0829

Bui Huu Tai: 0000-0002-2034-3786

Nguyen Xuan Nhiem: 0000-0002-1161-6498

Phan Van Kiem: 0000-0003-0756-6990

\section{References}

[1] Y. Lu and D.F. Chen (2009). Analysis of Schisandra chinensis and Schisandra sphenanthera, J Chromatogr. A. 1216, 1980-1990.

[2] Y. Ikeya, K. Sugama, M. Okada and H. Mitsuhashi (1991). Two lignans from Schisandra sphenanthera, Phytochemistry 30, 975-980.

[3] W.L. Xiao, S.X. Huang, R.R. Wang, J.L. Zhong, X.M. Gao, F. He, J.X. Pu, Y. Lu, Y.T. Zheng and Q.T. Zheng (2008). Nortriterpenoids and lignans from Schisandra sphenanthera, Phytochemistry 69,2 8622866.

[4] Y. Ikeya, E. Miki, M. Okada, H. Mitsuhashi and J.G. Chai (1990). Benzoylgomisin Q and benzoylgomisin P, two new lignans from Schisandra sphenanthera Rehd. et Wils, Chem. Pharm. Bull. 38, 1408-1411. 
[5] G. Carr, D. E. Williams, R. Ratnayake, R. Bandara, S. Wijesundara, T. Tarling, A. D. Balgi, M. Roberge, R. J. Andersen and V. Karunaratne (2012). Hortonones A to C, hydroazulenones from the genus Hortonia, J. Nat. Prod. 75, 1189-1191.

[6] D.F. Chen, S.X. Zhang, K. Chen, B.N. Zhou, P. Wang, L. M. Cosentino and K.H. Lee (1996). Two new lignans, interiotherins A and B, as anti-HIV principles from Kadsura interior, J. Nat. Prod. 59, 1066-1068.

[7] J. Slanina, G. Pachnikova, M. Čarnecká, L. Porubová Koubíková, L. Adámková, O. Humpa, K. Smejkal and I. Slaninová (2014). Identification of key structural characteristics of Schisandra chinensis lignans involved in P-glycoprotein inhibition, J. Nat. Prod. 77, 2255-2263.

[8] H.C. Huang, Y.C. Lin, A. E. Fazary, I.W. Lo, C.C. Liaw, Y.Z. Huang, S.S. Liou and Y.C. Shen (2011). New and bioactive lignans from the fruits of Schisandra sphenanthera, Food Chem. 128, 348-357.

[9] S. M. Seo, H. J. Lee, Y. K. Park, M. K. Lee, J. I. Park and K. H. Paik (2004). Lignans from the fruits of Schizandra chinensis and their inhibitory effects on dopamine content in PC12 cells, Nat. Prod. Sci. 10, 104-108.

[10] Y. Ikeya, H. Taguchi and I. Yosioka (1980). The constituents of Schizandra chinensis Baill. VII. The structures of three new lignans,(-)-gomisin K1 and (+)-gomisins K2 and K3, Chem. Pharm. Bull. 28, 2422-2427.

[11] N. X. Nhiem, N. H. Tung, P. Van Kiem, C. Van Minh, Y. Ding, J.H. Hyun, H.K. Kang and Y. H. Kim (2009). Lupane triterpene glycosides from leave of Acanthopanax koreanum and their cytotoxic activity, Chem. Pharm. Bull. 57, 986-989.

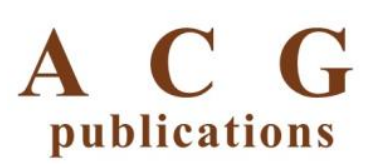

(C) 2020 ACG Publications 